\title{
Değişim çağında yeni nesil para: Kripto paraların avanataj ve dezavantajlarına yönelik inceleme
}

\section{A new generation currency in the era of change: A review on the pros and cons of cryptocurrencies}

\author{
Tuğkan Arıci ${ }^{1}$ \\ Hakan Kitapçı ${ }^{2}$ \\ Eray Fidan ${ }^{3}$ \\ 1 Arş. Gör., Gebze Teknik Üniversitesi İşletme Fakültesi, Türkiye, e-mail: tarici@gtu.edu.tr \\ 2 Prof. Dr ., Gebze Teknik Üniversitesi İşletme Fakültesi, Türkiye, e-mail: kitapci@gtu.edu.tr \\ 3 Gebze Teknik Üniversitesi İşletme Fakültesi, Türkiye, e-mail: erayf3@gmail.com
}

\section{ÖZ}

Satoshi Nakamoto tarafından 2008 yllında kaleme alınan "A Peer-to-Peer Electronic Cash System" makale ile hayatımıza giriş yapan sanal para (kripto para) konusu son yıllarda hem yatırımcıların hem dehükümetlerin dikkatini çekmektedir. Dağıtılmış ağlar aracılığıyla merkezileşmeyi yok eden ve herhangi bir otoriteye bağlı kalmadan işlem yapabilmeyi sağlayan kripto paralar, geleneksel para sistemlerinde bulunan aracı gibi dezavantajlı oluşumları aradan kaldıran, maliyetleri düşüren, daha hızlı ve güvenilir ödeme yöntemleri olarak ortaya çıkmaktadır. Finans ve girişimcilik başta olmak üzere paranın kullanım alanı ve kullanım yöntemlerinde çeşitli yenilikler ve kolaylıklar sunan kripto paralar, beraberinde getirmiş olduğu avantaj ve dezavantajları nedeniyle günümüzde anlaşılmaya çalışılan en önemli konu başlığı olarak karşımıza çıkmaktadır. Özellikle son dönemde Çin'in kripto para borsasına işlem yasağı getirmesiyle beraber kripto paraların mevcut durumu, hükümetlerin kripto paralara bakış açılarının neler olacağı ve değişen dünya düzeninde kripto paraların nasıl bir yer tutacağı merak konusu olmaya başlamıştır. Bu çalışmanın amacı kripto paralar üzerine literatürde yer alan mevcut çalışmaların incelenmesi sonucunda kripto para teknolojisinin hem yatırımcılar ve hükümetler için sağlayacağı avantaj ve dezavantajlarının neler olduğunun belirlenmesi hem de gelecek araştırmalar için araştırmacılara yol gösterilmesi hedeflenmiştir.

Anahtar kelimeler: Kripto para, Bitcoin, Blok zincir, Sanal para

JEL kodlar1: G29, M21, M48

Citation: Arıcı, T. \& Kitapçı, E. \& Fidan. E., Değişim çağında yeni nesil para: Kripto paraların avanataj ve dezavantajlarına yönelik inceleme. Holistic Economics. 2022; 1(1): 11-19. DOI: 10.55094/hoec.1.1.02 


\begin{abstract}
The subject of virtual currencies (crypto currencies), which entered our lives with the article "A Peer-to-Peer Electronic Cash System" written by Satoshi Nakamoto in 2008, has attracted the attention of both investors and governments in recent years. Cryptocurrencies, which eliminate centralization through distributed networks and enable transactions without being dependent on any authority, emerge as faster, less costly and more reliable payment methods that eliminate disadvantageous formations such as intermediaries in traditional money systems. Cryptocurrency, which offers various innovations and conveniences in the usage area and usage methods of money, especially in finance and entrepreneurship, emerges as the most important topic that is tried to be understood today due to the advantages and disadvantages it brings. Especially recently, with China's ban on cryptocurrency exchanges, the current situation of cryptocurrencies, the perspectives of governments on cryptocurrencies and the place of cryptocurrencies in the changing world order have started to be a matter of curiosity. The aim of this study is to determine the advantages and disadvantages of crypto money technology for both investors and governments as a result of examining the existing studies in the literature on cryptocurrencies and to guide researchers for future research.
\end{abstract}

Keywords: Cryptocurrencies, Bitcoin, Blockchain, Digital currencies

JEL codes: G29, M21, M48

\section{GİRIŞ}

Günümüzde hızla gelişen teknolojik gelişmeler beraberinde birçok farklı alanda yeniliği de getirmektedir. $\mathrm{Bu}$ yenilikler kimi zaman var olan sistemin etkinliğini destekleyip yapıcı karakteristik özellik taşırlarken, kimi zaman ise yıkıcı karakteristik özellikler sergilemektedir. Nitekim 21'nci yüzyılın başıyla beraber yüksek bir hıza kavuşan değişim rüzgârı, beraberinde de pek çok yıkıcı etkiyi getirmiştir. Günümüzde bu yıkıcı etkilere örnek olarak ise yapay zeka, nesnelerin interneti, robotik, endüstri 4.0, blok zincir ve kripto para teknolojileri gösterilmektedir.

Yıkıcı teknolojik değişimler günümüzde daha çok konuşuluyor olsa da aslında yeni bir kavram değildir.

Günümüzde çokça kullandığımız "sermaye" kelimesinin kökeni, milattan önceki dönemlerde değiş tokuş işlemlerine konu olan "sı̆̆gr $\mathrm{r}^{\text {" }}$ veya "çiftlik hayvanı" anlamına gelen Latince "Capitale" kelimesidir. Zaman içerisindeki teknolojik ve bilimsel ilerlemelere bağlı olarak sermaye kelimesinin anlamında da değişimler yaşanmış ve "para" ve "yatırım" için de kullanılmaya başlanmıştır (Ciğerim, 2020). Paranın tarihine baktığımızda da deniz kabukları ile başlayıp, madeni paralardan kâğıt birimlere tarih içerisinde pek çok süreç içerisinden geçtiğini görmeyiz (Camuz ve Destailleur, 2019). Günümüzde ise teknolojik gelişmelerle birlikte her alanda olduğu gibi para da tekrar değişimlere ayak uydurarak blok zincir teknolojisi ile dijitalleşmeye başlamıştır.

Paranın dijitalleşerek soyut bir hal almasıyla birlikte geleneksel para sistemleri de değişim göstermiştir. Günümüzde çokça işitmeye başladığımız kripto paralar, temelde herhangi bir otoriteye veya aracıya bağlı kalınmadan paranın dolaşmasına imkan tanıyan teknolojiler olarak karşımıza çıkmaktadır. Kripto para transferlerinin sanal ortamlarda mekan ve zamandan bağımsız olarak gerçekleşmesi, para transferlerinin herhangi bir hükümet, banka ya da otorite tarafından engellenememesi gibi pek çok avantaj ve dezavantajları da bulunmaktadır (Yildırım, 2019).

Kripto paraların hizla popüler hale gelmesiyle birlikte gerek yatırımcılar gerekse de hükümetler açısından yakından takip edilmeye başlanmış ve hükümetlerce çeşitli düzenlemeler hayata geçmiştir. Bu yasal düzenlemelerden en ilginci ise El Salvador'un kripto para birimlerinden biri olan Bitcoin'in resmi para birimi olarak tanınması ve tüm ülkede Bitcoin ödemelerinin kabul edilmesine imkan taniyan yasal düzenlemedir. El Salvador'un almış olduğu karar doğrultusunda, Bitcoin bir ödeme yöntemi 
olarak kabul edilmiştir ve El Salvador bu kararı alan ilk ülke olarak tarihe geçmiştir (BBC, 2021a). El Salvador'un aksine Çin hükümeti ise, bankalar üzerinden kripto borsalarına ve yatırımcılara hizmet verilmesini yasaklamış ve ülkede Bitcoin madenciliğiyle ilgili çeşitli önlemler alacaklarını ifade etmişlerdir (BBC, 2021b; Dinçer, 2021). Dünyanın en önemli ekonomik gücüne sahip Amerika Birleşik Devletleri, El Salvador ve Çin hükümetinin aldığı karardan farklı olarak; adil piyasa değeri 10.000 dolardan fazla olan kripto varlıkları alan işletmelerin de rapor edileceğini belirtmiştir (The American Families Plan, 2021). Dünyada yaşanan bu gelişmeleri ülkemiz açısından değerlendirdiğimizde ise ülkemizin yasaklayıcı bir politika gütmediğini aksine, 11. Kalkınma Plan'ında blok zincir tabanlı Dijital Merkez Bankası parasının uygulamaya konulmasını hedeflediğini görmekteyiz (Kalkınma Planı, 2019).

Bu çalışma kapsamında, son 10 yıl içerisinde literatürde ve dünya basınında kripto para piyasasına yönelik ortaya çıkan yeni gelişmelerin ülkelerin aldığı kararların incelenmesiyle kripto paranın geleceği ve avantaj ve dezavantajlarının netleștirilmesini hedeflemiştir.

\section{KRIPTTO PARA TANIMI VE GELIŞIMI}

Bitcoin ilk defa 2008'de Satoshi Nakamoto'nun kaleme almış olduğu "A Peer-to-Peer Electronic Cash System" isimli makalede bahsedilmiştir (Dulupçu vd., 2017). Nakamoto' nun çalışmasında bahsedilen Bitcoin sanal para teknolojilerinin çifte harcama ve güvenilirlik sorunlarına bir çözüm bulmak ve bireyler arası para transferlerini aracı kurumlara ihtiyaç duymadan düşük işlem maliyetiyle gerçekleştirmek amacıyla öne sürülen bir elektronik para sistemidir. Bu sistem kullanıcılar arasında gerçekleşen işlemlerin kayıtlarını bir aracı kurum yerine dağıtık bir CPU mimarisinde tutulmakta ve eşler arası işlemlerin doğruluğu Proof-of-Work (PoW) olarak isimlendirilen bir mutabakat yöntemiyle kontrol edilmektedir. Bitcoin'in sunduğu bu avantajlar sayesinde de kullanıcıların sistemi manipüle etmesi engellenmektedir (Nakamoto, 2008).
Amerika'da başlayıp tüm dünyayı etkisi altına alan 2008 krizi, ülkelerde işsizlik artışına ve GSYİH'nın ciddi anlamda düşmesine neden olmuştur. Yaşanan küresel ölçekli bu kriz sonucunda toplum gözünde banka ve finans kuruluşlarının itibarı da zedelenmiştir (Rejeb vd., 2021). Dünya bu sorunlarla mücadele ederken Satoshi Nakamoto'nun öneridiği Bitcoin, yüzyıllardır devam eden "kârları özelleştirirken zararları sosyalleştiren" ekonomik düzenin bir anlamda y1kılmasına ve finansal kurumlarına karşı yenilikçi bir yanıt olarak ortaya çıkmıştır (Lerer ve McGarrigle, 2018).

Bitcoin, yani kripto para, piyasaya ilk çıktığında sadece oyun sistemlerinde kullanılmaktayken, kullanımının ve popülerliğinin artmaya başlamasıyla mal ve hizmet alışverişlerinde de ödeme yöntemi olarak kullanılmaya başlandı. Öyle ki PayPal, Microsoft, DELL, Expedia gibi teknoloji devi firmalar ödemelerinde Bitcoin'i kullanmaya başladı ve bu sayede Bitcoin tüm dünyadaki bilinirliğini arttırdı (Dulupçu vd., 2017).

Bitcoin'in para piyasasında ortaya koyduğu yenilikçi bakışla beraber ikinci kripto para olan Ethereum piyasaya çıkmıştır. Ethereum blok zincir teknolojisini kullanarak dijital ortamda akıllı kontratlarI mümkün kılmış ve bu sayede merkezi veya merkeziyetsiz girişimlerin ve uygulamaların ortaya çıkabileceği ucu açık bir platform oluşturmuştur. (Blau vd., 2021). Bitcoin ve Ethereum'un geliştirdiği ve piyasaya önerdiğ $i$ teknolojiler sonucunda yatırımcılar yenilikçi ve yüksek kazançlar nedeniyle kripto borsalarına yönelmeye başlamıştır.

Bitcoin'in öncülüğünde ortaya çıkan kripto para dünyası, Etherium'un gelişiyle daha da canlanmıştır. Öyle ki günümüzde 300'den fazla kripto para borsasında işlem gören 10 bin adetten fazla kripto para bulunmaktadır. Kripto para piyasasının Temmuz 2021 itibariyle değeri 1.5 Trilyon ABD Dolarından fazladır ve kripto para hacminin \%46'sını Bitcoin, \%16'sını ise Etherium oluşturmaktadır (Coin Market Cap, 2021).

Kripto para teknolojisi, beraberinde getirdiği teknolojik yeniliğin yanı sıra dünya genelindeki değerinin 2 Trilyon ABD Doları seviyesine 
yaklaşıyor olması nedeniyle literatürde kendisine yer bulmuştur. Kripto para teknolojilerine yönelik gerçekleştirilen çalışmaların sayısı az olsa da aslında araştırmacılara kripto para teknolojisinin gelecek görünümü hakkında bazı ipuçları vermektedir. Örneğin Ekiz, (2019) yaptığı çalışmada kripto paraların Türk Vergi Sistemi KDV ve vergi mevzuatı bağlamında incelemiş ve bu incelemeyi yaparken farklı ülkelerin kripto paraları vergilendirme hususunda yürüttü çalışmaları karşılaştırmıştır. Çalışmada Türk Vergi Sisteminde vergiyi doğuran olayın kanunlarla yasak kabul edilmiş olsa da vergilendirilmesine engel teşkil etmediğini ve ayrıca kripto paraların nitelik açısından (para, emtia, finansal varlık) hangi türe dâhil olursa sisteme nasıl adapte edilebileceği konusunu açıklığa kavuşturmuştur.

Briere vd. (2015) kripto paraların erken aşaması sayılabilecek bir dönemde (2010-2013) bir yatırım portföyü çeşitlendirme aracı olarak faydalarını incelemişlerdir. Diğer yatırım araçlarıyla kripto paralar arasında gözlemlenenen düşük korelasyon sebebiyle çeşitlendirme için iyi bir yatırım aracı olabileceğinden fakat kriz zamanları bu yatırım araçları arasında korelasyonun arttı̆̆ bilindiği için tam anlamıla bu durumun sürekliliğinden emin olmadıklarından bahsetmişlerdir.

Dulupçu vd., (2017) Bitcoin'in değeriyle bilinirliğini inceledikleri çalışmada, Google üzerinden alınan Bitcoin'in aranma sayısıyla güncel değeri arasındaki ilişkiyi analiz etmişlerdir. Sonuç olarak Bitcoin'in fiyatı ile popülerliği arasında çok güçlü bir ilişki olduğunu ve nedenselliğin yönü popülariteden Bitcoin'in fiyatına doğru olduğunu, bunun anlamının ise Bitcoin'in fiyat hareketlerini popülaritesinin yönlendirmesinden kaynaklandığını yani Bitcoin'in bilinirliği arttıkça fiyatı da arttı̆ı çıkarımında bulunmuştur.

Blau vd., (2021) Bitcoin ve Bitcoin'in enflasyona karşı koruyucu özelliği gösterip göstermeyeceği sorusunu temel alarak zaman analiziyle bu tartışma çevresinde çıkarım elde etmeye çalışmıştır. Çalışmada Louis Merkez Bankası'nın 5 yıllık ileriye dönük enflasyon beklentisi oranlarıyla Bitcoin'in değeri arasında ilişkiyi incelenmiş ve sonuç olarak Bitcoin'in enflasyona karşı koruma görevi görebileceğini, Bitcoin'deki hareketlerin beklenen enflasyondaki değişikliklerden önce geldiğini ve bu nedenle, Bitcoin'in bir değişim aracı olarak kullanılabilecek bir metaya benzer şekilde davrandığı gözlemlemiştir.

Sarkodie vd., (2021) pandemi sürecinde Bitcoin ve Ethereum gibi market değeri büyük diğer coinler ile açıklanan vaka sayıları arasındaki ilişkiyi incelemişlerdir. Bu çalışma, küresel ekonomik belirsizlik ve kripto para birimi piyasa değerini, gerçekleşen değeri, ağ değerini ve işlem sinyallerini etkileyen piyasa sinyali şokunun temsilcisi olarak COVID-19 pandemisinin rolünü değerlendirmekte. Araştırmanın sonuçlarında kripto paraların durağan bir süreçte olmadıklarını ve zaman içinde piyasadaki fiyatlarının değişebileceğini ama pandemiye bağlı olarak sağlık sonuçlarının zayıf bağımlı bir süreçle devam ettiğini ulaşılmış. Çeşitli kripto para birimlerinin yapısal değerlendirmesi, COVID-19 pandemisi ile $\mathrm{N}$ şeklinde bir ilişki olduğu çıkarımında bulunmuştur.

İslam, (2019) blok zinciri teknolojisi tanıtmış, mevcut ve potansiyel kullanım alanlariyla ilgili bilgi vermiştir. Dünyadaki blok zinciri uygulamalara değinmiş, sistemin kendine özgü yapısı itibariyle sağlamış olduğu avantajlar anlatılırken blok zinciri teknolojisin önündeki en büyük engel dijital dönüşüme karşı oluşturulan önyargılı tutumlar olduğunu belirtmiş ve olası risklerden de bahsedilerek hem olumlu hem olumsuz değerlendirmesi yapılmıştır.

Ante, (2021) Elon Musk'in 2020 - 2021 yillarında twitter üzerinden kripto para borsasını büyük ölçüde etkileyen gönderilerinden yola çıkmış, gönderinin paylaşım tarihiyle ilgili kripto paranın grafiği arasındaki ilişki incelenerek, etkili ve tanınmış kişilerin sosyal medya faaliyetlerinin kripto para birimleri üzerinde sahip olabileceğ $i$ önemli etkiyi göstermiştir.

Karkkainen, (2021) yaptığı çalışmada dijital varlıklar için kaybetme korkusunu (FOMO) incelenmeye ve ölçeklemeye çalışmıştır. Çalışmada Ekonomik Kalkınma ve İşbirliği Örgütü (OECD) aracılığıyla elde edilen ve 
ICO'lara (ilk para birimi teklifi) karşı duyulan inançlarla alakalı anket verileriyle ICO'ların talep kısmında ki verilere bakılarak ICO pazarı analiz edilmiştir. Araştırmanın sonucunda ankette bulunan daha zengin grup üyelerinin bir FOMO pazarlama kampanyasıla çevrimiçi promosyoncular tarafından hedef alındığı ve bu etkileşim ICO sahipliğinin yaklaşık \%25'ini açıladığına ulaşılmıştır. Finansal memnuniyetsizlik gibi olumsuz duyguların hem ICO'ların farkındalığını hem de önceki ve mevcut ICO sahipliğini açıladığını bulmuşlardır.

Camuz ve Destailleur, (2019) ileride bir para birimi olarak kripto paraların Avrupa hükümetleri açısından iki farklı senaryoda potansiyelini incelemek amaciyla paranın düşünce okulunu, tarihsel gelişimini ve kripto paraların avantajlarıyla dezavantajlarını detaylı bir şekilde incelemişlerdir. Çalışmanın sonucunda yakın gelecekte ülkenin mevcut para birimini destekleyici ve alternatif sunan bir kripto para birimi kullanmanın, mevcut para birimini kripto para olmasından daha geçerli olacağı fikrine varılmıştır.

Dağlı, (2019) çalışmasında Bitcoin ve diğer kripto paralarınekonomikbüyüklükleri, Bitcoin'in diğer Kripto paralara karşı üstünlügündeki değişim ele alınmış, kara para ekonomisi bakımından incelenmiş ve kripto paraların yatırımtasarruf boyutu değerlendirilmiştir. Çalışmada birçok Kripto para birimi teknoloji ve yenilik bakımından Bitcoin'den üstün durumda olduğu bahsederken, Bitcoin'in dominans oranının en düşük olduğu dönemde bile piyasanın üçte birini oluşturduğuna dikkat çekmiştir. Bitcoin'in her ne kadar teknik bakımından yeterli olsa da kara para aklama ekonomisini etkileyebilecek büyüklükte olmadığından bahsetmiştir.

Kazak vd, (2020) yaptıkları çalışmada kripto paraların İslami finans sistemi içerisindeki durumunu ortaya koyarak Türkiye için İslami para ve finans sistemine uygun olacak şekilde bir kripto para model önerisi geliştirmişlerdir. "TRLCOIN" adı altında Merkez bankası tarafından çıkarılacak kripto para bir yandan İslam'ın şartlarını karşılanması diğer yandan ülkemiz için kripto paraların avantajlarından yararlanmamızı sağlaması amaçlanmıştır.
Literatürde yapılan çalışmalar göz önüne alındığında temelde kripto paraların; ülkelerin yasal vergilendirme sistemlerine engel teşkil etmeyeceği, yüksek kriz durumları hariç olmak üzere iyi bir yatırım aracı olduğu, enflasyon karşısında para değer kaybının engelleneceği ve Avrupa ülkeleri için gelecek için önemli bir para birimi olabileceğini ifade etmiştir. Ancak kripto paraların bu avantajlarının yanı sıra dezavantajları da olacağı öngörülmektedir. Özellikle kara para aklama ve manipülasyonlar sonucu ile yatırımciların olumsuz senaryolar yaşayabileceği ön görülmektedir.

\section{METODOLOJI}

$\mathrm{Bu}$ çalışma kapsamında kripto para teknolojisi üzerine literatürdeyer alan çalışmalar incelenerek kripto para teknolojisinin yatırımcılara, ülke ekonomilerine ve hükümetlere sağlayacağı avantaj ve dezavantajların neler olabileceği üzerinde incelemelerde bulunulmuştur.

Kripto para teknolojisi alanında yapılmış çalışmaları incelemek için Dergipark, Yükseköğretim Kurulu Tez Merkezi (YÖK Tez) ve Proquest veri tabanları kullanılmıştır. Yapılan aramalarda "Cyyptocurrencies", "Bitcoin", "Blokchain" ve "Digital Currencies" anahtar kelimeleri kullanılmış; güncel çalışmaların derinlemesine incelenmesi amaciyla 01.01.2016 tarihinden sonra yayınlanan çalışmalar incelenmiştir. İlgili veri tabanlarında yapılan incelemeler sonucunda 200'den fazla çalışma bulunmuştur ve bu çalışmalardan, araştırma amacımızla direkt ilgili olmayan çalışmaların çıartılmasıyla 20 çalışmanın derinlemesine incelenmesine karar verilmiştir.

Yapılan literatür incelemesinde kripto para teknolojisine yönelik gerçekleştirilen çalışmaların genellikle; "Kripto Paraların Muhasebeleştirilmesi", "Kripto Para Uygulamaları", "Kripto Paraların Değişim Süreci" gibi işletme biliminin finans ve muhasebe alanında çalışıldığı gözlemlenmiştir (Uysal, 2019; Deniz, 2020; Çakmak, 2019; Alpago, 2018; Topaloğlu, 2021). Ancak kripto para politikalarını destekleyen ülkelerin ne gibi fırsatlar ya da tehtitlerle karşılaşabileceklerine ilişkin herhangi bir çalışmaya rastlanılmamıştır. 
$\mathrm{Bu}$ nedenle çalışmanın kapsamı bu düzlemde tutulmuş ve kripto paraların yatırımcılara, ülke ekonomilerine ve hükümetlere sağlayacağı olası avantaj ve dezavantajlar incelenmiştir. Araştırma sonucunda elde edilen bulgular bir sonraki bölümde açıklanmıştır.

\section{BULGULAR}

Gelişim ve değişimin dinamize olduğu günümüzde kripto para ve blok zincir teknolojisinin dünyaya ve özellikle de finans sektörüne yıkıcı etkilere sahip çeşitli yenilikler getirdiği/getireceği inkar edilemez bir gerçektir. Satoshi Nakamoto'nun 2008 yılında temellerini attığ1 "yeni dünya para birimi" kripto para teknolojisi henüz çok yeni bir teknolojidir ve manipülasyona açık olması nedeniyle de yatırımclar açısından halen güvenli bir yatırım aracı olarak görülmemektedir. Öte yandan 2021 yılı içerisinde kripto para borsasının çok dalgalı olması ve Elon Musk'ın açıklamalarıyla bir gecede binlerce insanın yatırımlarının büyük bir bölümü kaybetmesi gibi olaylar nedeniyle de kripto para teknolojisinin popülerliği ve beraberinde getirdiği teknoloji hamlesi değersizleşmektedir. Kripto paraların, düşük işlem maliyeti, daha yüksek işlem etkinliği, işlem güvenliği ve gizliliği, portföy çeşitlendirmedeki faydaları, alternatif finansman bulma çözümü, bulunduğu bölgenin finansal katılımı arttırması dolayısıyla finans sektörünün zaman içerisinde gelişimi gibi birçok doğrudan veya dolaylı avantajları sayesinde bulunduğu ekosisteme büyük katkılar sunduğu görülmektedir (Rejeb vd., 2021).

Kripto para teknolojisinin beraberinde getirmiş olduğu avantajların yanısıra pek çok dezavantajı olduğu da bilinen bir diğer gerçektir. Proof of Work gibi mutabakat yöntemini kullanan Bitcoin ve diğer kripto paralar doğası gereği işlevini sürdürebilmek ve güvenliğini sağlayabilmek için yüksek işlemci (CPU) gücüne ihtiyaç duymaktadır. Bu nedenle de kripto para gelişimi aşamasında büyük enerji tüketimi ortaya çıkmaktadır ve bu durumun çevreye olan olumsuz etkisi, kripto para teknolojisine duyulan en büyük endişelerden biridir. Kripto para teknolojilerinin enerji tüketimi üzerindeki olumsuz etkisinin azaltılabilmesi için ülkeler, yenilenebilir enerji kaynaklarının kullanımına yönelik çeşitli teşvikler ve vergi muafiyeti gibi yöntemlerle yaygınlaştırmaya çalışmaları sürdürmektedir (Yegen, 2019). Kripto para madenciliği alanında artan yenilebilir enerji kullanımı ile ilgili, 2020 yılında Cambridge Alternatif Finans Merkezi'nin yaptığı bir araştırmaya göre, Proof of Work madencilerinin \%76'sının operasyonlarının bir bölümünde yenilenebilir enerji kaynaklarını kullandığını ve toplamda Proof of Work madenciliğinde kullanılan enerjinin \%39'unun yenilenebilir enerji kaynakları ile elde edildiği tespit edilmiştir (Blandin vd., 2020).

Kripto para teknolojisinin sahip olduğu en büyük dezavantajlardan bir diğeri ise kolayca manipüle edilebilir oluşudur. Günümüzde Merkez Bankalarına bağlı olarak çalışan borsaların belirli kuralları, seans süreleri ve devre kesici uygulamaları bulunmaktadır. Ancak yapısı gereği kripto para borsalarında bu tür bir denetim mekanizması bulunmamaktadır. Öte yandan borsanın tüm dünya genelinde sürekli açık olması da manipülasyonun daha kolay yapilıyor olmasina neden olmaktadir. Benzer şekilde otoritenin bulunmadığ 1 bir ortam kötü niyetli kişiler için fırsatlar yaratmaktadır. Kripto para borsasına yönelik kuralların henüz çizilmemiş olması, hızlı servet elde etmek için kulaktan dolma bilgiler kripto para borsasina yatırım yapan yatırımcların zarara uğramasına neden olmaktadır.

Hükümetler açısından incelediğimizde ise kripto paranın bir diğer dezavantajı ise merkeziyetsiz oluşu ve takip edilememesi nedeniyle yaşanacak olan sorunlardır. Özellikle kara para aklama, vergi kaçırma, karaborsa gibi yasa dışı aktiviteler ile uluslararası terörizm aktivitelerinin finanse edilebilmesi gibi amaçlar için kripto paraların kullanabilir olması hükümetlerin en büyük endişelerinden biridir. Bu yüzden bu konular ülkelerin regülasyonda öncelikli vermesi gereken ve küresel anlamda standartların belirlenmesi gereken önemli konu başlıkları olarak karşımıza çıkmaktadır. Tüm ülkeler için optimal bir regülasyonun yada vergi kanunu varlığından söz etmek bu aşamada güç olsa da her ülke kendi şartları altında bu kuralları 
kesinlikle belirlemelidir.

\section{SONUÇ}

İçerisinde bulunduğumuz 21'nci yüzyıl teknoloji alanında olduğu gibi finans anlamında da devrim niteliğinde yeniliklere yol açmış ve parasal sistemlerde de değişim ve dönüşüm çă̆ı başlamıştır. Satoshi Nakamoto tarafından 2008 yılına kadar ise tüm dünyadaki tüm para ve türevleri merkezi bankalar ve resmi para otoriteleri tarafından tedavüle çıkartılıyordu. Ancak Satoshi Nakamoto'nun dünyaya Bitcoin isimli sanal parayı tanıtmasıyla resmi merciler olmadan da paranın dolaşıma sokulmasına olanak tanınmıştır (Alpago, 2018).

Kripto para ile merkezi para politikalarının benzer noktaları bulunmaktadır. Her ikisi de temelde hiçbir değere sahip değildir ve onları değerli kılan şey değişim aracı olmaları ile ödeme gücüne sahip olmalarıdır. Özellikle kıt kaynak oluşları ve belirli kurallara bağlı olarak piyasaya arz ediliyor olmaları en önemli benzerlikleridir. Merkezi paralarda kurallar kamu otoritesiyle belirlenirken kripto para sisteminde bu durum, özel yöntem ve programlarla dizayn edilmiş sistem kurucuları tarafından belirlenmektedir. Para politikaları açısından devrim niteliğinde olan bu gelişmeler yeniliklere açık ve meraklı insanlar tarafından kullanılmaya başlanmış ve zamanla yatırım aracına dönüşüştür. Geçen 12 yıl içerisinde de ilk sanal para olan Bitcoin'in değeri 50 Bin ABD Doları seviyesine ulaşmış ve zaman içerisinde hem alt yapı tekniği hem de dijital para açısından benzer pek çok coin piyasaya girmiştir.

Kripto paraların yakın bir gelecekte ekonomik yaşamın merkezinde olacağı ve zamanla yaşama tam entegre olacağı aşikardır. Ancak kripto para teknolojisi, merkezi para politikalarından farklı olarak gelişmiş alt yapı yatırımına, güçlü sermayeye ve belli seviyede teknolojik yetkinliğe ihtiyaç duymaktadır. Haliyle belli bir gelişmişlik seviyesine sahip toplumlar kripto para teknolojilerinde öncü konumda olacaktır. Sonuç olarak da kripto para teknolojisine öncelikli yatırım yapan hem yatırımcıların hem de ülkelerin önemli avantajlar elde edeceği öngörülmektedir.
Kripto para teknolojisinin beraberinde getirmiş olduğu en büyük dezavantaj ise hiç şüphesiz ki, merkezi otoriyeye ihtiyaç duyulmadan kripto paraların geliştirilebiliyor olmasıdır. $\mathrm{Bu}$ durum kara para aklanması, kazancin vergilendirilmemesi ve yatırımcıların mağdur edilmesi gibi pek çok sorunu beraberinde getirmektedir. Nitekim ülkelerde bu sorunları göz önünde bulundurarak kripto para teknolojilerine temkinli yaklaşmakta ve destek vermek yerine kısıtlayıcı önlemler almaktadır..

Dünya genelinde ülkelerin bu anlamda birbirlerinden farklı kararlar verdiğini görmekteyiz. Örneğin Çin katı bir tutumla birçok kripto para faaliyetini ülke genelinde yasaklamıştır. Ancak El Salvador, Malta, İngiltere ve İsviçre gibi birçok ülke kendi ülkelerindeki kripto para ve blok zincir uygulamalarını önünü açan yenilikçi kararları uygulamaya koymuştur. Bunların yanı sıra bu ülkeler kripto para piyasasında olan yatırımcıları çeşitli vergi regülasyonları, düşük operasyon ve/veya düşük enerji maliyetleri gibi teşvik edici yöntemlerle kendi ülkelerine çekmeye çalışmaktadır (Islam, 2019). Kripto paraların sağlayacağı avantaj ve kolaylıklar gözönüne alındığında ülkelerin kripto paralara yönelik olan tutumlarının toptan yasaklayıcı ya da kontrolsüz serbestlik şeklinde olmaması gerektiğini önermekteyiz.

Çalışma kapsamında elde edilen tüm bilgiler 1şığında; yatırımcılara büyük zorluklar çıarmayan yasal düzenlemelerin kesinlikle oluşturulması, illegal faaliyetlerin engellenmesine yönelik gerekli yatırımların ülkelerce finanse edilmesi, kripto para madencilerinin yenilenebilir enerji kaynaklarını kullanmalarına imkan tanıyan teşvik ve destek mekanizmalarınin kurgulanmasının ve halkın güvenliğinin yanı sıra yaşanabilecek olumsuz durumlara yönelik eğitimlerin hızlıca sunulmasının ülkeler için daha faydalı olacağını ve gelişen teknolojiden olabildiğince yüksek oranda faydalanmasının önemli olduğu bu çalışma kapsamında da tespit edilmiştir.

Turizm, e-ticaret, vergi ödemeleri gibi merkezi sistemlerin kolaylıkla kontrol mekanizmaları 
kurabileceği sistemlerin geliştirilmesi bu anlamda önem arz etmektedir. Ülkelerin bu sistemleri en kisa sürede bünyelerinde kullanmaya başlamasıyla hem teknoloji erken aşamada ve yakın zamanda kontrol edilebilecek hem de dünya genelinde böyle bir yapıda öncül teşkil edileceği için kripto para borsasının ülke içerisine kaydırılmasına imkan tanınmış olacaktır.

\section{KAYNAKÇA}

Ante, L. (2021). “How Elon Musk's Twitter Activity Moves Cryptocurrency Markets", Blokchain Research Lab, 16, pp: 1-13.

Alpago, H. (2018). "Bitoin'den Selfcoin'e Kripto Para”, Uluslararası Bilimler Araştırmalar Dergisi, 3(2), ss: 411-428.

BBC. (2021a). Bitcoin: El Salvador, Kripto Parayı Resmi Para Birimi İlan Eden İlk Ülke Oldu.

Erişim Adresi: https://www.bbc.com/turkce/haberlerdunya-57415131 Erişim Tarihi: 09.06.2021

BBC. (2021b). Bitcoin, Ethereum, Dogecoin: Çin'in İşlem Yasağı Kararı Sonrası Kripto Paralar Sert Düşüş Yaşadı.

Erişim Adresi: https://www.bbc.com/turkce/haberlerdunya-57170586 Erişim Tarihi: 19.05.2021

Blandin, A., Pieters, G. C., Wu, Y., Dek, A., Eisermann, T., Njoki, D., Taylor, S. (2020). 3rd Global Cryptoasset Benchmarking Study. Cambridge: Cambridge Centre For Alternative Finance. Doi: https://doi.org/10.2139/ ssrn.3700822

Blau, B. M., Griffith, T. G., Whitby, R. J. (2021). "Inflation and Bitcoin: A Descriptive Time-Series Analysis", Economics Letters, 203, pp: 1-5. Doi: https:// doi.org/10.1016/j.econlet.2021.109848

Brière, M., Oosterlinck, K., Szafarz, A. (2015). “Virtual Currency, Tangible Return: Portfolio Diversification With Bitcoin", Journal of Asset Management, 16(6), pp: 365-373. Doi: https://doi.org/10.1057/jam.2015.5

Camuz, S., Destailleur, M. (2019). In View of The History of Money, Is The (Crypto) Currency A Possible
Future For European Governments?. Louvain School of Management: Digital Access to Libraries.

Coin Market Cap (2021). Erişim Adresi: https:// coinmarketcap.com Erişim Adresi: 20.06.2021

Çakmak, M. (2019). “Kripto Paraların Gelişim Süreci, Blok Zincir Teknolojisi ve Kripto Paraların Türkiye'de Vergilendirilmesi", Marmara Üniversitesi Sosyal Bilimler Enstitüsü İktisat Anabilim Dalı Uluslararası İktisat Bilim Dalı Yüksek Lisans Tezi, İstanbul.

Dağlı, İ. (2019). “Kripto Paraların Dünya Ekonomisindeki Makroekonomik Boyutu ve Türk Lirası Bazında Yatırım-Tasarruf Aracı Olarak Kripto Paralara Genel Bir Bakış", Journal of Emprical Economic and Social Sciences, 1(1), ss: 40-49.

Deniz, E. A. (2020). “Finansal Piyasalarda Kripto Para Uygulamaları: Kripto Para Fiyatlarını Etkileyen Faktörler", Işık Üniversitesi Sosyal Bilimler Enstitüsü İşletme Anabilim Dalı Muhasebe ve Denetim Bilim Dalı Yüksek Lisans Tezi, İstanbul.

Dinçer, A. (2021). Çin Kripto Para Yasağ $\mathrm{M}_{1}$ ? İşte Tarihsel Gerçekler. Erişim Adresi:https://kriptokoin. com/cin-kripto-para-yasagi-mi/ Erişim Tarihi: 20.06.2021

Dulupçu, M. A., Yiğit, M., Genç, A. G. (2017). “Dijital Ekonominin Yükselen Yüzü: Bitcoin'in Değeri İle Bilinirliği Arasındaki İlişkinin Analizi", Süleyman Demirel Üniversitesi İktisadi ve İdari Bilimler Fakültesi Dergisi, 22, ss: 2241-2259.

Ekiz, Y. (2019). “Bir Ödeme Aracı Olarak Kripto Para Birimlerinin Gelişimi VeTürkiye'de Vergilendirilmesi”, Marmara Üniversitesi Sosyal Bilimler Enstitüsü Yüksek Lisans Tezi, İstanbul.

İslam, A. (2019). "Blok Zincir Teknolojisi ve Kripto Paralar: Mevcut Durum, Potansiyel ve Risk Analizi", Marmara Üniversitesi Sosyal Bilimler Enstitüsü Yüksek Lisans Tezi, İstanbul.

Kalkınma Planı (2019). On Birinci Kalkınma Planı (2019-2023). TC. Cumhuriyeti Cumhurbaşkanlığ Strateji ve Bütçe Başkanlığı. Erişim Adresi: https:// www.sbb.gov.tr/wp-content/uploads/2019/07/ OnbirinciKalkinmaPlani.pdf

Karkkainen, T. (2021). "FOMO in Digital Assets", SSRN Electronic Journal, pp: 1-18.

Kazak, H., Çeker, O., Erkan, H. (2020). “Kripto Paraların İslam Para Sistemi Açısından Uygunluğu: Türkiye İçin Uygulanabilir İslami Kripto Para Modeli Önerisi", Journal of Accounting Finance and Auditing Studies (JAFAS), 6(3), ss: 58-92. Doi: https://doi. org/10.32602/jafas.2020.018

Lerer, M., McGarrigle, C. (2018). "Art In The Age of 
Financial Crisis", Visual Resources, 34 (1-2), pp: 1-12. Doi: https://doi.org/10.1080/01973762.2018.1455355

Nakamoto, S. (2008). “Bitcoin: A Peer-to-Peer Electronic Cash System", Satoshi Nakamoto Institute Working Paper. Erişim Adresi: http://nakamotoinstitute.org/ bitcoin/

Özer, G., Ciğerim, E., Gök, M.Ş. (2020). “Entelektüel Sermaye ve Bilgi Yönetimi Stratejilerinin Firma Performansina Etkisi", Business and Management Studies: An International Journal, 8(5), ss: 4611-4645.

Rejeb, A., Rejeb, K., G. Keogh, J. (2021). "Cryptocurrencies in Modern Finance: A Literature Review", Etikonomi, 20(1), pp: 93-118. Doi: https:// doi.org/10.15408/etk.v20i1.16911

Sarkodie, S. A., Ahmed, M. Y., Owusu, P. A. (2021). "Covid-19 Pandemic Improves Market Signals of Cryptocurrencies-Evidence From Bitcoin, Bitcoin Cash, Ethereum, and Litecoin", Finance Research Letters, pp: 1-10. Doi: https://doi.org/10.1016/j. frl.2021.102049

The American Families Plan (2021). Fact Sheet: The American Families Plan. Erişim Adresi: https:// www.whitehouse.gov/briefing-room/statementsreleases/2021/04/28/fact-sheet-the-american-familiesplan/

Topaloğlu, B. (2021). "Kripto Paraların Devlet Otoriteleriyle Entegrasyonu", Düşünce ve Toplum Sosyal Bilimler Dergisi, 4, ss: 244-258.

Uysal, Ü. (2019). “Kripto Para ve Kripto Paranın Ticarette Kullanımı: Girişimcilerin ve Yatırımcıların Kripto Paraya İlişkin Tutumlarının İncelenmesi", Muğla Sıtkı Koçman Üniversitesi Sosyal Bilimler Enstitüsü İşletme Anabilim Dalı Yüksek lisans Tezi, Muğla.

Yegen, B. (2018). “Yenilenebilir Enerji Kaynaklarında Gelir Vergisi Esnaf Muaflığı Uygulaması", 5rd International Congress on Political, Economic and Social Studies (ICPESS), 26-29 Ekim 2018. Niğde, Türkiye.

Yıldırım, M. (2019). “Blok Zincir Teknolojisi, Kripto Paralar ve Ülkelerin Kripto Paralara Yaklaşımları", Bartın Üniversitesi İktisadi ve İdari Bilimler Fakültesi Dergisi, 10(20), ss: 265-277. 